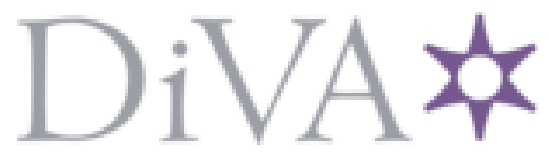

http://www.diva-portal.org

\title{
Postprint
}

This is the accepted version of a paper published in Manual Therapy. This paper has been peerreviewed but does not include the final publisher proof-corrections or journal pagination.

Citation for the original published paper (version of record):

Johansson, A C., Karlsson, H. (2016)

The Star Excursion Balance Test: Criterion and divergent validity on patients with femoral acetabular impingement.

Manual Therapy, 26: 104-109

http://dx.doi.org/10.1016/j.math.2016.07.015

Access to the published version may require subscription.

N.B. When citing this work, cite the original published paper.

Permanent link to this version:

http://urn.kb.se/resolve?urn=urn:nbn:se:mdh:diva-32909 


\section{The Star Excursion Balance test: Criterion and divergent validity on patients with femoral acetabular impingement}

Ann-Christin Johansson ${ }^{1}$

Hillevi Karlsson ${ }^{2}$

1. Department of Physiotherapy, School of Health, Care and Social Welfare

Mälardalen University, Box 883

SE- 72123 Västerås

Sweden

ann-christin.johansson@mdh.se

2. Department of Orthopedics,

Hospital of Västmanland County

SE- 72189 Västerås

Sweden

hillevi.karlsson@1tv.se

Corresponding author:

Ann-Christin Johansson

School of Health, Care and Social Welfare

Mälardalen University

Box 883

SE- 72123 Västerås, Sweden

ann-christin.johansson@mdh.se 


\section{Key words}

The Star Excursion Balance Test

Femoral acetabular impingement

Criterion validity

Divergent validity 


\begin{abstract}
Background: A valid functional test, evaluating dynamic balance control, might be valuable clinic tool for evaluation of treatment outcome on patients with femoral acetabular impingement (FAI).
\end{abstract}

Objectives: The aim of this study was to evaluate criterion and divergent validity of the Star Excursion Balance Test (SEBT) on patients with bilateral FAI- changes, with unilateral clinical symptoms.

Method: In this cross sectional correlational and comparative study fifteen patients with bilateral FAI with unilateral symptoms and 15 controls participated. Criterion validity was determined by analyzing agreement between SEBT and The Copenhagen Hip and Groin Outcomes Score (HAGOS), The Hip Sports Activity Scale (HSAS), pain and leg strength on FAI patients. Divergent validity was determined by comparing SEBT on FAI patients with controls and by comparing SEBT on patient's symptomatic and asymptomatic hips.

Results/Findings: SEBT posterolateral and posteromedial direction had high criterion validity in relation to HAGOS subscale pain intensity and symptoms ( $r s=0.75, p=0.001$, respectively $\mathrm{rs}=0.70, \mathrm{p}=0.004)$. Criterion validity was low in relation to HAGOS subscales sports, recreation, participation in physical activity and quality of life. SEBT in the posterolateral and posteromedial direction had good divergent validity $(p=0.006$, respectively $\mathrm{p}=0.001$ ) and in the posterolateral direction SEBT could differentiate between patient's symptomatic and asymptomatic hip ( $\mathrm{p}=0.005)$.

Conclusions: SEBT in posterolateral and posteromedial direction has good criterion validity in relation to pain and other symptoms. In the posterolateral and posteromedial 
direction SEBT also had divergent validity. Clinically it is recommended to combine SEBT in the posterolateral and posteromedial direction with other measurements on patients with FAI. 


\section{INTRODUCTION}

Femoral acetabular impingement syndrome (FAI) derives from morphological changes and symptoms related to the hip in young and middle-aged active adults. These are known as cam lesions (loss of femoral head-neck offset), pincer lesions (global acetabular over coverage) or a combination of the two, which is most the common (Bedi \& Kelly, 2013). The typical changes can cause impingement between the neck and the rim of the acetabulum, resulting in hip-related pain and disability (Bedi \& Kelly, 2013; Rubin, 2013). The prevalence of FAI pathology is unknown in the general population (Levy, 2011), but the typical morphological findings exist in 10-74 $\%$ of asymptomatic individuals (Reiman \& Thorborg, 2015).

FAI can induce changes in muscle forces and strain in the pelvic region and can affect hip add- and abductors, the hamstrings muscles and iliopsoas and contribute to abnormal stress and asymmetric load between the femoral head and the acetabulum in standing and in repetitive movements. This in turn can lead to instability of the hip joint and reactive hip pain in extreme flexion movements (Bedi \& Kelly, 2013).

Non-operative treatments for FAI have been suggested to be the first treatments of choice Wall et al concluded in their review that physical therapy have some benefits to patients, but studies on the outcome of physiotherapy treatment are needed. (Wall, Fernandez, Griffin, \& Foster, 2013). To evaluate treatment, and possibly also for diagnostic purposes, functional performance tests can add valuable information. At present, it is unclear which functional performance tests are most appropriate to use in FAI patients (Kivlan \& Martin, 2012), there is a great demand for functional tests that can determine pathology and treatment outcome (Reiman \& Thorborg, 2015). 
The Star Excursion Balance Test (SEBT) is a functional performance test to assess dynamic postural control (Winter, Patla, \& Frank, 1990). The SEBT has shown validity in relation to hip abductor muscle function (Hubbard, Kramer, Denegar, \& Hertel, 2007; Norris \& Trudelle-Jackson, 2011) and a relationship to the hip range of movement (ROM) (Robinson \& Gribble, 2008). The SEBT has been used in research and in clinical practice to examine lower extremity injuries (Gribble, Hertel, \& Plisky, 2012). The test is suitable for young, physically active individuals but its validity has not been evaluated in relation to patients with FAI (Gribble et al., 2012). The aim of this study was to evaluate criterion and divergent validity of the SEBT on FAI patients. 


\section{MATERIAL AND METHODS}

The study was cross-sectional with a correlational and comparative design.

Criterion validity was determined by comparing the agreement between the SEBT and the Copenhagen Hip and Groin Outcome Score (HAGOS), the Hip and Sports Activity Scale (HSAS), pain intensity and the chair stand test.

Divergent validity was determined between FAI patients and a group of individuals with no symptoms of FAI. Additionally, it was analysed whether SEBT differed between a patient's symptomatic and asymptomatic hips.

\section{$\underline{\text { Study samples }}$}

All participants were recruited from the orthopaedic department of a regional hospital in a Central Swedish city between February and April 2014.

\section{FAI group}

Twenty-nine patients, all of whom were referred to the physiotherapy department at the same hospital, were checked for eligibly and asked to participate. Those patients had all x-rayverified bilateral morphological changes and were diagnosed by two experienced orthopaedic surgeons. They were scheduled for arthroscopic treatment and were referred to the physiotherapy department for a pre-operative examination.

Inclusion criteria: Diagnosed FAI with one symptomatic hip/side and age 16 to 60 years. Exclusion criteria were: Previous injury and/or diseases (except FAI) which could influence balance and strength in the lower extremities, spontaneous improvement since decision for arthroscopic treatment, or deficient Swedish language.

Seven of the 29 eligible patients had bilateral clinical symptoms and x-ray-verified FAI, two had trochanteritis, one had hip osteoarthritis, one had another disease affecting balance, one 
declined to participate, one failed to show up and one had markedly improved at the second measurement. Fifteen patients fulfilled the study criteria and participated in the study.

\section{Comparison group}

Fifteen individuals with similar age and gender profile as the patient group, but without symptoms of FAI were recruited from the personnel staff of the transport, service and logistic department in the same hospital. Inclusion and exclusion criteria for this group were similar as those for the FAI group. There were no significant differences between the FAI and comparison groups outside of pain and the FAI diagnosis (Table 1). 
Table 1. Description of the study samples, medians (max-min)

\begin{tabular}{|c|c|c|}
\hline & $\begin{array}{l}\text { Patients with unilateral } \\
\text { symptomatic FAI, } \\
\mathrm{n}=15\end{array}$ & $\begin{array}{l}\text { Comparison group } \\
n=15\end{array}$ \\
\hline Age & $25(17-44)$ & $32(20-46)$ \\
\hline Sex, number, women/men, & $9 / 6$ & $8 / 7$ \\
\hline Body weight, kg & $73(60-115)$ & $67(56-104)$ \\
\hline Height, $\mathrm{cm}$ & $173(163-202)$ & $170(159-188)$ \\
\hline $\begin{array}{l}\text { Leg length, cm } \\
\text { right } \\
\text { left }\end{array}$ & $\begin{array}{l}91(82-110) \\
91(82-110)\end{array}$ & $\begin{array}{l}86(79-98) \\
87(79-98)\end{array}$ \\
\hline Physical activity level HSAS' $(0-8)$ & $3(0-5)$ & $3(1-8)$ \\
\hline $\begin{array}{l}\text { Hip anterior impingement test positive on } \\
\text { the symptomatic side, number }\end{array}$ & 14 & - \\
\hline $\begin{array}{l}\text { Hip anterior impingement test positive on } \\
\text { the asymptomatic side, number }\end{array}$ & 1 & - \\
\hline Pain duration, months, median (max-min) & $24(4-60)$ & - \\
\hline FAl type, number, mixed/pincer/cam & $2 / 13 / 0$ & - \\
\hline
\end{tabular}

1.The Hip Sports Activity Scale

In connection to the physiotherapy visit, the patients who met the criteria received oral and written information about the study and were asked to participate by the physiotherapist who did the preoperative test. Written consent was obtained from all participants.

\section{Measurements}

All participants were tested using the SEBT and HSAS. The HAGOS, pain intensity and one leg raise tests were only performed on the FAI patients. All measurements were performed by the same physiotherapist (HK) who had several years' experience of this patient group. 
Patient-reported hip and groin disability was measured by the Copenhagen Hip and Groin Outcome Score (HAGOS), which comprises 37 items in six Likert subscales, each with grading from 0 to 4 where 0 represents no symptom/disability and 4 represents constant symptom/disability. The subscales are symptoms ( 7 items), pain (10 items), physical function in daily living (5 items), function in sports and recreational activities (8 items), participation in physical activities (2 items) and hip- and/or groin-related quality of life (5 items). Each subscale is computed by a matrix, and the total score can vary from zero to 100 (Thorborg, Holmich, Christensen, Petersen, \& Roos, 2011).

The HAGOS has acceptable psychometric properties (Munro \& Herrington, 2010) (Thorborg et al., 2011). The HAGOS has been recommended as suitable for patients undergoing treatment for FAI (Harris-Hayes et al., 2013; Thorborg et al., 2011). The test has been culturally adopted and translated into Swedish (Thomee et al., 2014).

Physical activity level was measured by the Hip Sports Activity Scale (HSAS). This scale is based on the Tegner activity level scale (Tegner \& Lysholm, 1985) and ranges from 0 to 8 , where 0 represent no physical exercise and 8 represents competition in sports at a national or international top level. The scale was adjusted to hip-related disability by an expert panel and has been reported to have excellent test-retest reliability in both German and English, with intraclass correlation coefficients of 0.94 and 0.96 , respectively, and acceptable content and construct validity (Naal et al., 2013). It has been adopted and translated into Swedish (Sansone et al., 2014; Thomee et al., 2014). In this study, the patients reported current and desired activity level.

Pain intensity at activity during the most recent week was measured by the Visual Analogue Scale (VAS) on a 0-10 scale. (Price, McGrath, Rafii, \& Buckingham, 1983).

Functional strength was measured by a one leg raise test from sitting to standing. The test was a modification of the $30 \mathrm{~s}$ chair stand test, accomplished on one leg only, from a chair 
with a height of $44 \mathrm{~cm}$. The patients crossed their arms in front of their chest and the opposite leg was unsupported and extended in front of the body. The number of correct rises during 30 and $60 \mathrm{~s}$ were measured. The original test has shown satisfying test-retest reliability (Jones, Rikli, \& Beam, 1999).

Dynamic balance was measured by the Star Execution Balance Test (SEBT) (Gray, 1995) The test is a series of single-limb squats where the patient stands on the leg to be tested and uses the non-stance limb to reach maximally and touch a point along one of eight designated lines on the ground. The lines are arranged in a grid that extends from a centre point and are $45^{\circ}$ from one another, formatting a stylistic star. The directions of the pointing leg are anteriomedial, anteriolateral, medial, lateral, posterior, posteriomedial and posteriolateral. Good reliability and validity of this test have been reported, and the test has been recommended for both healthy people and for people with injuries to the lower extremities (Gribble et al., 2012). In this study, the test was modified and only the anterior, posteriolateral and posteriomedial directions (all measurements followed this order) (Hertel, Braham, Hale, \& Olmsted-Kramer, 2006) were tested. These directions have previously been related to hip function (Norris \& TrudelleJackson, 2011). The participants did four training tests in each direction before measurement and was instructed as follows; starting position; standing on both legs with hands in the waist, than try to reach as far as possible with extended toes and wrist, along the measure line, away from the measured leg, in respectively direction. Weight bearing should be on the standing leg. Finally return to standing on both legs. Controlled trunk movement and knee bending was allowed during measurement. The measurement was invalid if weight bearing was taken on the leg which was reached out, if balance was lost, if the any part of the foot sole on the standing leg left the floor, or if the individual not managed to go back to the starting position. The test was repeated until the participant had completed three faultless attempts in each direction and means of the reached distance of the three measurements, in each direction, were calculated. 
Leg length was measured with a measuring tape from the spina iliaca superior anterior to the medial malleolon in the supine position. The leg length was than divided by the mean measured for each direction of the SEBT and the quotient was multiplied by 100 to obtain results for the proportion of leg length for each individual (excursion distance/leg length) x $100=\%$ MAXD (Robinson \& Gribble, 2008).

\section{Procedure}

Before the tests were performed, all individuals warmed up for ten minutes by cycling on an exercise bike. The patients did first the SEBT on the asymptomatic leg and then on the symptomatic leg, and the same order was followed for the one leg raise test. The healthy individuals without FAI only did the SEBT test on the dominant leg, which was determined by how they responded to the question "which leg would you use to kick a ball?" All tests were performed without shoes. The HAGOS questionnaire was sent to the patients with the letter of attendance, and the patients brought the questionnaire when they came to the physiotherapy department.

\section{$\underline{\text { Statistics }}$}

A power analysis carried out prior to the study showed that a total of 26 participants, 13 in each group, were needed to detect a clinically significant mean score of $10 \mathrm{~cm}$ difference between patients with FAI and individuals without FAI, with $80 \%$ power. To allow for possible dropouts we decided to include 15 individuals with diagnosed FAI and 15 individuals without any symptoms of FAI, for a total of 30 individuals. A $10 \mathrm{~cm}$ difference was based on our clinical experience and on four previous studies in which comparisons between a group with injuries to the lower extremities and a healthy group had been performed (Gribble et al., 2012). 
Non-parametric statistics were used for the analyses of relations, differences and correlations. The strength of the correlation was judged according to Carter Lubinsky $\left(\mathrm{r}^{\mathrm{s}} 0.26-0.49\right.$ low, $0.50-0.69$ moderate, $0.70-0.89$ high and $0.90-1.0$ very high) (Carter, Lubinsky, \& Domholdt, 2011). Differences between patients with FAI and controls were analysed with the independent Mann-Whitney U test. Mean values were based on all measurements on both legs for the individuals without FAI, whereas for patients with FAI the mean value was based on all values of the symptomatic side. Differences between patients symptomatic and asymptomatic side were analysed with Wilcoxon dependent test. A p-value $\leq 0.05$ was considered to be significant.

\section{Ethics}

The patients and the individuals without FAI were informed that their participation was voluntary, that data collection would be handled with confidentially, and that they were free to withdraw from the study any time without giving any reason and without influence on coming treatment. Further ethical aspects were considered based on the World Medical Association Declaration of Helsinki (World Medical Association, 1964). The study was approved as a master work at Mälardalen University, Sweden. Ethical aspects were considered and guaranteed by the University (Karlsson, 2014). 


\section{RESULTS}

Hip disability, physical activity level, pain intensity, functional strength and dynamic balance for FAI patents

Results of the measurements are presented in Table 2. The FAI patients had the lowest rates on the HAGOS subscales for physical activity, quality of life, and sports and recreation. The SEBT showed the most side difference in the posterolateral direction $(4.8 \%)$ for the FAI patients, (Table 2). 
Table 2. Results of measurements on FAI patients.

\begin{tabular}{|c|c|}
\hline Test & Medians (min-max) \\
\hline \multicolumn{2}{|l|}{ HAGOS } \\
\hline symptoms & $61(25-89)$ \\
\hline pain intensity & $53(2-83)$ \\
\hline ADL & $65(30-70)$ \\
\hline sport and rekreation & $47(6-84)$ \\
\hline participating in physicl activity & $25(0-75)$ \\
\hline quality of life & $30(15-75)$ \\
\hline \multicolumn{2}{|l|}{ HSAS } \\
\hline at present & $3(0-5)$ \\
\hline desired & $5(0-5)$ \\
\hline Pain at activity, VAS $(0-10)$ & $7(2-8)$ \\
\hline Chair stand test $30 \mathrm{~s}$, symptomatic side & $6(0-12)$ \\
\hline Chair stand test $\mathbf{3 0} \mathrm{s}$, asymptomatic side & $7(0-14)$ \\
\hline Chair stand test $60 \mathrm{~s}$, symptomatic side & $12(0-25)$ \\
\hline Chair stand test $60 \mathrm{~s}$, asymptomatic side & $13(0-27)$ \\
\hline \multicolumn{2}{|l|}{ SEBT } \\
\hline anterior symptomatic side & $70(60-77)$ \\
\hline anterior asymptomatic side & $78(68-91)$ \\
\hline posterolateral symptomatic side & $78(68-91)$ \\
\hline posterolateral asymptomatic side & $84(72-94)$ \\
\hline posteromedial symptomatic side & $76(47-88)$ \\
\hline posteromedial asymptomatic side & $77(50-91)$ \\
\hline
\end{tabular}

Criterion validity

Association between the SEBT and HAGOS

The strongest and most significant correlation was between the SEBT in the posterolateral and posteromedial directions and the HAGOS subscale for pain intensity $\left(\mathrm{r}^{\mathrm{s}}=0.75, \mathrm{p}=0.001\right.$; $\mathrm{r}^{\mathrm{s}}=0.70, \mathrm{p}=0.004$, respectively). 
There were significant moderate correlations between the SEBT in both the posterolateral and posteromedial directions in relation to the HAGOS subscale for symptoms $\left(\mathrm{r}^{\mathrm{s}}=0.65\right.$, $\mathrm{p}=0.009 ; \mathrm{r}^{\mathrm{s}}=0.55, \mathrm{p}=0.034$, respectively). Likewise, there was a moderate correlation between the SEBT in the posterolateral direction and the HAGOS subscale for ADL function $\left(r^{\mathrm{s}}=0.56, \mathrm{p}=0.031\right)$. On the contrary, there were no associations between the SEBT and HAGOS subscales for sports and recreation, participating in physical activity, and quality of life.

There were no significant correlations between the SEBT in the anterior direction and the subscales of the HAGOS (Table 3).

Associations between the SEBT and HSAS regarding pain intensity at activity

There were no significant associations between the SEBT, irrespective of direction, and the current or desired HSAS. The pattern was similar regarding the association between the SEBT and VAS for pain intensity at activity, with the strongest association between the SEBT in the posterolateral direction and pain, but this association was not significant $\left(r^{\mathrm{s}}=-\right.$ 0.453, $\mathrm{p}=0.090)$ (Table 3.)

\section{Association between the SEBT and functional strength (one leg raise)}

There was a significant moderate correlation between the SEBT in the posterolateral direction and one leg raise at both $30 \mathrm{~s}$ and $60 \mathrm{~s}\left(\mathrm{r}^{\mathrm{s}}=0.6, \mathrm{p}=0.01 ; \mathrm{r}^{\mathrm{s}}=0.5, \mathrm{p}=0.04\right.$, respectively) and between the SEBT in the posteromedial direction and one leg raise at $30 \mathrm{~s}$ $\left(r^{s}=0.6, p=0.02\right)$. The corresponding association in the SEBT in the posteromedial direction was not significant when the test was accomplished at $60 \mathrm{~s}\left(\mathrm{r}^{\mathrm{s}}=0.5, \mathrm{p}=0.09\right)$. There was no 
significant correlation between the SEBT in the anterior direction and one leg raise. (Table

3.) 
Table 3. Correlation coefficients $r^{s}$ and (p-values) for associations between SEBT and HAGOS subscales, HSAS, VAS and chair stands test for the symptomatic hip of FAI patients, $n=15$.

\begin{tabular}{|c|c|c|c|}
\hline & $\begin{array}{c}\text { SEBT } \\
\text { anterior }\end{array}$ & $\begin{array}{c}\text { SEBT } \\
\text { posterolateral }\end{array}$ & $\begin{array}{c}\text { SEBT } \\
\text { posteromedial }\end{array}$ \\
\hline HAGOS subscales & & & \\
\hline symptoms & $-0.11(0.707)$ & $0.65(0.009)$ & $0.55(0.034)$ \\
\hline pain intensity & $0.01(0.960)$ & $0.75(0.001)$ & $0.70(0.004)$ \\
\hline ADL & $-0.01(0.726)$ & $0.56(0.031)$ & $0.046(0.088)$ \\
\hline sport and recreation & $-0.03(0.929)$ & $0.16(0.566$ & $0.19(0.491$ \\
\hline $\begin{array}{c}\text { participating in physical } \\
\text { activity }\end{array}$ & $-0.01(0.985)$ & $-0.07(0.812)$ & $-0.16(0.570)$ \\
\hline quality of life & $-0.01(0.990)$ & $0.36(0.188)$ & $0.24(0.399)$ \\
\hline HSAS & & & \\
\hline current & $-0,04(0,892)$ & $0,09(0,756)$ & $0,01(0,964)$ \\
\hline desired & $-0,15(0,607)$ & $-0,19(0,501)$ & $-0,18(0,519)$ \\
\hline Pain intensity in activity & & & \\
\hline VAS (0-10) & $0,05(0,852)$ & $-0,45(0,090)$ & $-0,39(0,149)$ \\
\hline Chair stands test & & & \\
\hline $30 \mathrm{~s}$ & $0,17(0,551)$ & $0,62(0,013)$ & $0,58(0,022)$ \\
\hline $60 \mathrm{~s}$ & $0,18(0,529)$ & $0,54(0,037)$ & $0,46(0,088)$ \\
\hline
\end{tabular}

\section{Divergent validity}

\section{Differences between patients with FAI and individuals without FAI}

The median value for the SEBT in the posterolateral direction for patients with FAI on the symptomatic side was $78 \%$ MAXD, whereas the corresponding value for individuals without FAI was $90 \%$ MAXD ( $\mathrm{p}=0.006$ ). Likewise, there was a significant difference of $9 \%$ $(\mathrm{p}=0.001)$ in the SEBT in the posteromedial direction between the symptomatic side in patients with FAI and the individuals without FAI.

There was, however, also a significant difference of $8 \%$ MAXD $(p=0.008)$ between patients with FAI on the asymptomatic side and individuals without FAI in the SEBT in the posteromedial direction (Table 4). 
Differences in the SEBT between the symptomatic and asymptomatic legs in patients with FAI

The median value of the SEBT in the posterolateral direction for patients with FAI on the symptomatic side was $77.6 \%$ and for the asymptomatic side was $82.4 \%$. This difference was significant $(\mathrm{p}=0.005)$ (Table 4$)$. 
Table 4. Median values (min - max) of SEBT (\% of limb length for each individual, excursion distance/leg length) $\mathrm{x} 100=\%$ MAXD, for patients with FAI, symptomatic side, individuals without FAI and patients with FAI asymptomatic side.

$\mathrm{p}^{1}$ - value represent difference between FAI patients symptomatic side and individuals without FAI

$\mathrm{p}^{2}$ - value represent differences between FAI patients asymptomatic side and individuals without FAI.

\begin{tabular}{|l|l|l|l|l|l|}
\hline & $\begin{array}{c}\text { FAI patients } \\
\text { symptomatic } \\
\text { side }\end{array}$ & $\begin{array}{c}\text { Individuals } \\
\text { without FAI }\end{array}$ & $\mathbf{p}^{\mathbf{1}}$-value & $\begin{array}{c}\text { FAI patients } \\
\text { asymptomatic } \\
\text { side }\end{array}$ & $\mathbf{p}^{\mathbf{2}}$-value \\
\hline $\begin{array}{l}\text { SEBT } \\
\text { anterior }\end{array}$ & $70(60-77.4)$ & $73.5(62.8-79.2)$ & 0.22 & $71.1(63.1-81.4)$ & 0.46 \\
\hline $\begin{array}{l}\text { SEBT } \\
\text { posterolateral }\end{array}$ & $77.6(68.3-91)$ & $89.6(75.7-101)$. & 0.006 & $82.4(71.8-94.3)$ & 0.89 \\
\hline $\begin{array}{l}\text { SEBT } \\
\text { posteromedial }\end{array}$ & $75.5(47.2-88.4)$ & $84.7(76-98.4)$ & $<0.001$ & $76.9(50-91)$ & 0.008 \\
\hline
\end{tabular}




\section{DISCUSSION}

The study is the first of its kind to investigate the validity of a functional dynamic balance test for patients with FAI. The SEBT in the posterolateral and posteromedial directions had high to moderate criterion validity in relation to the HAGOS subscales for pain intensity and symptoms, as well the as posterolateral direction and ADL function, whereas the criterion validity of the SEBT in relation to the HAGOS subscales for sports and recreation, participation in physical activities and quality of life was low. In addition, the criterion validity for the SEBT in relation to functional leg strength was moderate, and generally criterion validity was low for the SEBT in the anterior direction.

The results indicate that the criterion validity for the SEBT on FAI patients is limited for the entire FAI construct. According to the model International Classification of Functioning (ICF) which classify health and disability from body, individual, and societal perspectives (WHO, 2001), SEBT refers to body functions and structure whereas HAGOS comprises both body functions and symptoms but also dimensions of activities and participation. An important purpose of both conservative and surgical treatment of FAI is to reduce patients' pain and symptoms (Byrd, 2014; Philippon et al., 2007), and in relation to these entities, the SEBT in the posterolateral and posteromedial directions seems relevant to use as a functional test.

The SEBT is known to measure dynamic balance in the lower extremities, the test requires muscle strength, neuromuscular control, core stability, ROM, balance, coordination and weight bearing ability (Gribble et al., 2012). In patients with FAI, muscle forces and strain in the pelvic region are supposed to affect hip add- and 
abductors (Bedi \& Kelly, 2013). Norris et al. found that the medial reach of the SEBT elicited activation of the gluteus medius at $49 \%$ of maximal volitional isometric contraction. (Norris \& Trudelle-Jackson, 2011). It is known that FAI patients have reduced hip abductor (Hubbard et al., 2007), flexion (Casartelli et al., 2011; Nepple et al., 2015), adduction and external rotation muscles (Casartelli et al., 2011). The significant relation between functional leg strength and SEBT in the posterolateral and posteromedial directions indicates that strength reduction is involved in the decreased ability to execute the SEBT in these directions.

There was a significant $(\mathrm{p}=0.006) 12 \%$ MAXD difference in the SEBT in the posterolateral direction and, likewise, a significant $(\mathrm{p}=0.001) 9.2 \%$ MAXD difference in the posteromedial direction between patients with FAI and healthy controls without FAI. In a previous study where SEBT was measured on patients with chronic low back pain, a significant $9 \%$ MAXD difference between patients and healthy individuals was found in the posteromedial direction and corresponding difference in the posterolateral direction was $13 \%$ MAXD (Shankar Ganesh, Chhabra, \& Mrityunjay, 2015), these results are in accordance with the differences found in our study between the FAI patients and the controls. According to Munro et al. a SEBT of 6-8 \% MAXD is the smallest detectable difference (Munro \& Herrington, 2010), as the significant difference we found between the patients and the individuals without symptoms was slightly above this benchmark we value our findings as clinically relevant.

It was also interesting that there was a significant difference in the SEBT in the posteromedial direction, with a median of $7.8 \%$ MAXD between patients with FAI on the asymptomatic side and the controls. It is possible that SEBT in the 
posterolateral direction is sensitive to changes the patients had in their asymptomatic hip, even if they did not have clinical symptoms. It is also notable that the difference in medians between the patients' asymptomatic side and the controls was more pronounced than the difference between the patients' symptomatic and asymptomatic sides (1.4\% MAXD). One explanation to this finding could be that the SEBT is dependent on function in both legs. If the range of movement is restricted in the pointing leg, it will influence the result of the SEBT. In the functional leg strength test, however, no comparable difference was found. This could indicate that the functional dynamic balance is affected at an early stage in patients with FAI, which might be captured by the SEBT. A reduced performance in the SEBT possibly indicates that neuromuscular function not is optimal, and Philsky PJ et al (2006) gave some support to this assumption through their findings that the SEBT is a reliable and predictive measure of lower extremity injuries in high school basket players (Plisky, Rauh, Kaminski, \& Underwood, 2006).

One limitation of this study is that our control group was not imaged to ensure the absence of FAI. According to Reinman and Kristian Thorborg, radiologic findings of cam and pincer morphology can exist in 10-74 \% of asymptomatic individuals (Reiman \& Thorborg, 2015).

In addition, the sample size was small, and the representation of the entire FAI population in the FAI group can be questioned. However, based on our power calculation, and in relation to the study aims, our sample size was sufficient. The power calculation was, however, uncertain because it was based on previous studies on individuals with different injuries in the lower extremities and not on patients with 
FAI. However, the difference found between patients with FAI and individuals without FAI was in accordance with our assumption (a $10 \%$ MAXD).

The study also has some strengths. All SEBT tests were performed by the same experienced physiotherapist (HK). Criterion validity was examined by analysing whether the results of the SEBT were consistent with the HAGOS, HSAS, VAS and Chair Stand Test. All of these measurements have good reliability and validity on hip patients (Jones et al., 1999; Katz \& Melzack, 1999; Litcher-Kelly, Martino, Broderick, \& Stone, 2007; Naal et al., 2013; Thomee et al., 2014; Thorborg et al., 2011) and both the HAGOS and HSAS have previously been tested on patients with FAI (Sreedharanunni et al., 2015; Thomee et al., 2014).

\section{Conclusion}

SEBT in posterolateral and posteromedial direction has good criterion validity in relation to pain and other symptoms, in these directions SEBT also had divergent validity and could successfully differentiate between healthy individuals and FAI patients. Clinically, SEBT restricted to the posterolateral and posteromedial direction, could be used as measurements in the evaluation of FAI patients it is recommended as a complement to other measurements. 


\section{REFERENCES}

Bedi, A., \& Kelly, B. T. (2013). Femoroacetabular impingement. J Bone Joint Surg Am, 95(1), 8292. doi: 10.2106/JBJS.K.01219

Byrd, J. W. (2014). Femoroacetabular impingement in athletes: current concepts. Am J Sports Med, 42(3), 737-751. doi: 10.1177/0363546513499136

Carter, R. E., Lubinsky, J., \& Domholdt, E. (2011). Rehabilitation Research (K. Falk Ed. 4th ed.). St Louis, Missouri: Elsevier

Casartelli, N. C., Maffiuletti, N. A., Item-Glatthorn, J. F., Staehli, S., Bizzini, M., Impellizzeri, F. M., \& Leunig, M. (2011). Hip muscle weakness in patients with symptomatic femoroacetabular impingement. Osteoarthritis Cartilage, 19(7), 816-821. doi: 10.1016/j.joca.2011.04.001

Gray, G. W. (1995). Lower Extremity Functional Profile. Michigan: Wynn Marketing Inc Adrian.

Gribble, P. A., Hertel, J., \& Plisky, P. (2012). Using the Star Excursion Balance Test to assess dynamic postural-control deficits and outcomes in lower extremity injury: a literature and systematic review. J Athl Train, 47(3), 339-357. doi: 10.4085/1062-6050-47.3.08

Harris-Hayes, M., McDonough, C. M., Leunig, M., Lee, C. B., Callaghan, J. J., \& Roos, E. M. (2013). Clinical outcomes assessment in clinical trials to assess treatment of femoroacetabular impingement: use of patient-reported outcome measures. J Am Acad Orthop Surg, 21 Suppl 1, S39-46. doi: 10.5435/JAAOS-21-07-S39

Hertel, J., Braham, R. A., Hale, S. A., \& Olmsted-Kramer, L. C. (2006). Simplifying the star excursion balance test: analyses of subjects with and without chronic ankle instability. J Orthop Sports Phys Ther, 36(3), 131-137. doi: 10.2519/jospt.2006.36.3.131

Hubbard, T. J., Kramer, L. C., Denegar, C. R., \& Hertel, J. (2007). Correlations among multiple measures of functional and mechanical instability in subjects with chronic ankle instability. J Athl Train, 42(3), 361-366.

Jones, C. J., Rikli, R. E., \& Beam, W. C. (1999). A 30-s chair-stand test as a measure of lower body strength in community-residing older adults. Res Q Exerc Sport, 70(2), 113-119. doi: 10.1080/02701367.1999.10608028

Karlsson, H. (2014). Validitet av the Star Excursion Balance Test för funktionell dynamisk balans hos patienter med femuroacetabulärt inklämningssyndrom. (Master), Mälardalen University, Västerås

Katz, J., \& Melzack, R. (1999). Measurement of pain. Surg Clin North Am, 79(2), 231-252.

Kivlan, B. R., \& Martin, R. L. (2012). Functional performance testing of the hip in athletes: a systematic review for reliability and validity. Int I Sports Phys Ther, 7(4), 402-412.

Levy, B. A. (2011). Screening for femoroacetabular impingement in asymptomatic adolescent athletes. Arthroscopy, 27(e190).

Litcher-Kelly, L., Martino, S. A., Broderick, J. E., \& Stone, A. A. (2007). A systematic review of measures used to assess chronic musculoskeletal pain in clinical and randomized controlled clinical trials. J Pain, 8(12), 906-913. doi: 10.1016/j.jpain.2007.06.009

Munro, A. G., \& Herrington, L. C. (2010). Between-session reliability of the star excursion balance test. Phys Ther Sport, 11(4), 128-132. doi: 10.1016/j.ptsp.2010.07.002

Naal, F. D., Miozzari, H. H., Kelly, B. T., Magennis, E. M., Leunig, M., \& Noetzli, H. P. (2013). The Hip Sports Activity Scale (HSAS) for patients with femoroacetabular impingement. Hip Int, 23(2), 204-211. doi: 10.5301/hipint.5000006

Nepple, J. J., Goljan, P., Briggs, K. K., Garvey, S. E., Ryan, M., \& Philippon, M. J. (2015). Hip Strength Deficits in Patients With Symptomatic Femoroacetabular Impingement and Labral Tears. Arthroscopy. doi: 10.1016/j.arthro.2015.04.095 
Norris, B., \& Trudelle-Jackson, E. (2011). Hip- and thigh-muscle activation during the star excursion balance test. J Sport Rehabil, 20(4), 428-441.

Philippon, M. J., Schenker, M. L., Briggs, K. K., Kuppersmith, D. A., Maxwell, R. B., \& Stubbs, A. J. (2007). Revision hip arthroscopy. Am J Sports Med, 35(11), 1918-1921. doi: 10.1177/0363546507305097

Plisky, P. J., Rauh, M. J., Kaminski, T. W., \& Underwood, F. B. (2006). Star Excursion Balance Test as a predictor of lower extremity injury in high school basketball players. $J$ Orthop Sports Phys Ther, 36(12), 911-919. doi: 10.2519/jospt.2006.2244

Price, D. D., McGrath, P. A., Rafii, A., \& Buckingham, B. (1983). The validation of visual analogue scales as ratio scale measures for chronic and experimental pain. Pain, 17(1), 45-56.

Reiman, M. P., \& Thorborg, K. (2015). Femoroacetabular impingement surgery: are we moving too fast and too far beyond the evidence? Br J Sports Med, 49(12), 782-784. doi: 10.1136/bjsports-2014-093821

Robinson, R., \& Gribble, P. (2008). Kinematic predictors of performance on the Star Excursion Balance Test. J Sport Rehabil, 17(4), 347-357.

Rubin, D. A. (2013). Femoroacetabular impingement: fact, fiction, or fantasy? AJR Am J Roentgenol, 201(3), 526-534. doi: 10.2214/AJR.13.10913

Sansone, M., Ahlden, M., Jonasson, P., Thomee, C., Sward, L., Baranto, A., ... Thomee, R. (2014). A Swedish hip arthroscopy registry: demographics and development. Knee Surg Sports Traumatol Arthrosc, 22(4), 774-780. doi: 10.1007/s00167-014-2840-9

Shankar Ganesh, G., Chhabra, D., \& Mrityunjay. (2015). Efficacy of the Star Excursion Balance Test in detecting reach deficits in subjects with chronic low back pain. Physiother Res Int, 20, 9-15.

Sreedharanunni, S., Chhabra, S., Hira, J. K., Bansal, D., Sharma, P., \& Das, R. (2015). betaThalassemia Intermedia Caused by Compound Heterozygosity for $\mathrm{Hb}$ Lepore-Hollandia and beta-Thalassemia is Rare in the Indian Population. Hemoglobin, 39(5), 362-365. doi: 10.3109/03630269.2015.1064004

Tegner, Y., \& Lysholm, J. (1985). Rating systems in the evaluation of knee ligament injuries. Clin Orthop Relat Res(198), 43-49.

Thomee, R., Jonasson, P., Thorborg, K., Sansone, M., Ahlden, M., Thomee, C., . . Baranto, A. (2014). Cross-cultural adaptation to Swedish and validation of the Copenhagen Hip and Groin Outcome Score (HAGOS) for pain, symptoms and physical function in patients with hip and groin disability due to femoro-acetabular impingement. Knee Surg Sports Traumatol Arthrosc, 22(4), 835-842. doi: 10.1007/s00167-013-2721-7

Thorborg, K., Holmich, P., Christensen, R., Petersen, J., \& Roos, E. M. (2011). The Copenhagen Hip and Groin Outcome Score (HAGOS): development and validation according to the COSMIN checklist. Br J Sports Med, 45(6), 478-491. doi: 10.1136/bjsm.2010.080937

Wall, P. D., Fernandez, M., Griffin, D. R., \& Foster, N. E. (2013). Nonoperative treatment for femoroacetabular impingement: a systematic review of the literature. $P M R, 5(5), 418$ 426. doi: 10.1016/j.pmrj.2013.02.005

WHO. (2001). ICF: International Classification of Functioning, Disability and Health. Geneva Switzerland: WHO. .

Winter, D. A., Patla, A. E., \& Frank, J. S. (1990). Assessment of balance control in humans. Med Prog Technol, 16(1-2), 31-51.

World Medical Association. (1964). World Medical Association Declaration of Helsinki: Ethical Principles for Medical Research Involving Human Subjects. Adopted by the 18th WMA General Assembly, Helsinki. Revised in Tokyo 2004. 